\title{
Evaluation the efficacy of optimized two-step-administration therapy with ceftazidime/avibactam for treating Extensively drug-resistance (XDR) Pseudomonas aeruginosa pulmonary infections: a Pharmacokinetic/pharmacodynamic analysis
}

Yixin Kang

Chinese People's Liberation Army General Hospital

Junchang Cui ( $\backsim$ guoguoyoumeng@163.com )

Chinese People's Liberation Army General Hospital

\section{Research Article}

Keywords: extensively drug resistance Pseudomonas aeruginosa, ceftazidime-avibactam, optimized two-step-administration therapy, Monte Carlo simulations

Posted Date: February 28th, 2022

DOI: https://doi.org/10.21203/rs.3.rs-1330208/v1

License: (a) (i) This work is licensed under a Creative Commons Attribution 4.0 International License. Read Full License 


\section{Abstract}

Background: The objective of this pharmacokinetic (PK)/pharmacodynamic (PD) analysis was to evaluate the efficacy of different dosing regimens of ceftazidime-avibactam (CZA) for the treatment of extensively drug-resistance (XDR) Pseudomonas aeruginosa pulmonary infections by using optimized two-step-administration therapy (OTAT) and traditional infusion (TI).

Methods: We used Monte Carlo simulations (MCS) to integrate PK parameters with PD parameters to assess the adequacy of ceftazidime-avibactam dosing for XDR $P$. aeruginosa pulmonary infections. We obtained pharmacokinetic parameters from a previously published study and pharmacodynamic parameters from the international network for optimal resistance monitoring (INORM). Dosing models were as follows: $2.5 \mathrm{~g}$ q8h, $2.5 \mathrm{~g}$ q6h, $4 \mathrm{~g}$ q8h, $4 \mathrm{~g}$ q6h, $1.25 \mathrm{~g} \mathrm{q} 8 \mathrm{~h}, 1.25 \mathrm{~g} \mathrm{q} 6 \mathrm{~h}$, and $0.94 \mathrm{~g} \mathrm{q} 12 \mathrm{~h}$.

Results: MCS showed that the cumulative fraction of response (CFR) of all dosing regimens of OTAT was higher than $90 \%$. Similarly, the probability of target attainments (PTAs) of all dosing regimens of OTAT at MICs of 16-32 mg/L was higher than those of TI. Based on the models, PK/PD goals were met with OTAT regimens even with high MICs (>16 mg/L) compared with traditional infusion intervals.

Conclusion: Our work indicated that OTAT with sufficient pharmacokinetic exposures could improve the efficacy of CZA for XDR P. aeruginosa pulmonary infections.

\section{Background}

The infection of extensively drug resistance (XDR) Pseudomonas aeruginosa is associated with prolonged hospital stays, increased mortality, and health care costs. Moreover, it has become a severe problem for the daily work of doctors from every department [1].

Ceftazidime is a wide-spectrum third-generation cephalosporin, and it has outstanding safety and efficacy for the treatment of $P$. aeruginosa. Avibactam is a novel non- $\beta$-lactams $\beta$-lactamase inhibitor with a broad enzyme inhibition spectrum. Furthermore, it can prevent hydrolysis of ceftazidime. Ceftazidime and avibactam have similar pharmacokinetic (PK) parameters, for example, the volume of distribution $\left(\mathrm{V}_{\mathrm{d}}\right)$ and protein bindings (PBs) [2]. This allows the two drugs to be combined in a fixed ratio, resulting in better antibacterial effects. The EUCAST MIC distribution website (https://mic.eucast.org/Eucast2) shows the susceptibility rate for ceftazidime-avibactam (CZA) against the $P$. aeruginosa strains in vitro was $80.5 \%$. Whereas the in vitro study showed potent activity of CZA against other gram-negative bacteria (K. pneumoniae and Escherichia coli strains) with susceptibility rates of $86.4 \%$ and $91.6 \%$, respectively [3].

Clinical studies found that the efficacy of CZA for $P$. aeruginosa was unfavorable. In a REPROVE trial, a total of 356 patients with nosocomial pneumonia received CZA (2.5 g q8h dosing regimen and adjusted per renal function). [4]. In this study, CZA has the lowest clinical cure rate (64.3\%) and microbiological response rate $(42.9 \%)$ for treating $P$. aeruginosa infections when compared to meropenem. Similarly, Stone et al. pooled data from 5 different phase III trials, and they found that favorable microbiological response rates for CZA against multidrug resistance (MDR) P. aeruginosa was 57.1\% [5]. However, favorable microbiological response rates for Enterobacteriaceae infections range from 70.6-79.3\% [5].

Eguchi et al. (2010) found that optimized two-step-administration therapy (OTAT) with sufficient meropenem pharmacokinetic exposures could be important for improving the effectiveness of the $P$. aeruginosa treatment [6]. First-step infusion can rapidly reach the loading drug concentration, and the second-step infusion can continuously maintain efficacious drug exposures. Therefore, we speculated that OTAT is optimal for the coverage of XDR P. aeruginosa. To test our hypothesis, we conducted a pharmacokinetic/ pharmacodynamic analysis. Monte Carlo simulations (MCS) can integrate pharmacokinetic parameters with pharmacodynamic parameters to assess the efficacy of CZA for XDR $P$. aeruginosa pulmonary infections [7]. Therefore, the objective of our study was to evaluate the efficacy of CZA for the treatment of XDR P. aeruginosa if administered via OTAT and traditional infusion (TI).

\section{Materials And Methods}

\subsection{MIC distributions}

We obtained MIC distributions of CZA against 689 XDR $P$. aeruginosa isolates from the international network for optimal resistance monitoring (INFORM) program, as listed in Table I [8]. The database was selected because it included a total of 7452 . aeruginosa strains, most of which were isolated from patients with pulmonary infections (50.5\%) [8].

\subsection{Dosing regimens}

We adjusted various dosing models of CZA against XDR P. aeruginosa according to the simulated patient's degree of renal dysfunction. All simulated dosing regimens were listed in Table II. For patients with normal renal function ( $\left.\mathrm{CL}_{\mathrm{CR}}>51 \mathrm{ml} / \mathrm{min}\right)$, the standard regimen was $2.5 \mathrm{~g}$ q8h $(2 \mathrm{~h}$ infusion). The previously published clinical studies confirm the poor efficacy of CZA against MDR P. aeruginosa. We simulated dosing regimens of increasing the dose of CZA (4g $\mathrm{q} 8 \mathrm{~h})$, shortening the dosing interval $(2.5 \mathrm{~g} \mathrm{q} 6 \mathrm{~h})$ and applying both of these methods together ( $4 \mathrm{~g}$ q6h). For OTAT, the dosing regimen was: a rapid infusion of $1.25 \mathrm{~g}(0.5 \mathrm{~h}$ infusion) in the first step and a continuation of the remaining $1.25 \mathrm{~g}(2 \mathrm{~h}$ infusion) in the second step. Simulated patients received the above antiinfective treatment every 8 hours. Similarly, OTAT dosing regimens for normal renal function patients were $1.25 \mathrm{~g}(0.5 \mathrm{~h}$ infusion) $+1.25 \mathrm{~g}(2 \mathrm{~h}$ infusion) $\mathrm{q} 6 \mathrm{~h}$, $2 \mathrm{~g}(0.5 \mathrm{~h}$ infusion $)+2 \mathrm{~g}$ (2h infusion) $\mathrm{q} 8 \mathrm{~h}$, and $2 \mathrm{~g}(0.5 \mathrm{~h}$ infusion $)+2 \mathrm{~g}\left(2 \mathrm{~h}\right.$ infusion) $\mathrm{q} 6 \mathrm{~h}$. For patients with $30 \mathrm{ml} / \mathrm{min}<\mathrm{CL}_{\mathrm{CR}} \leq 50 \mathrm{ml} / \mathrm{min}$, dosing regimens for TI were $1.25 \mathrm{~g}$ q8h and $1.25 \mathrm{~g}$ q6h, for OTAT were $0.625 \mathrm{~g}(0.5 \mathrm{~h}$ infusion) $+0.625 \mathrm{~g}$ ( $2 \mathrm{~h}$ infusion) q8h and $0.625 \mathrm{~g}(0.5 \mathrm{~h}$ infusion) $+0.625 \mathrm{~g}(2 \mathrm{~h}$ infusion) 
q6h. For patients with $16 \mathrm{ml} / \mathrm{min}<\mathrm{CL}_{\mathrm{CR}} \leq 30 \mathrm{ml} / \mathrm{min}$, dosing regimens for Tl were $1.25 \mathrm{~g}$ q8h and $0.94 \mathrm{~g}$ q $12 \mathrm{~h}$, for OTAT were $0.47 \mathrm{~g}(0.5 \mathrm{~h}$ infusion) $+0.47 \mathrm{~g}$ (2h infusion) q12h [9].

\subsection{PK/PD modeling}

We obtained PK parameters of CZA from a previous publication by Stein et al. (2018) [2]. This study included ten critically ill patients with lower respiratory tract infections. The mean clearance and $V_{d}$ for ceftazidime were $6.1 \pm 3.8 \mathrm{~L} / \mathrm{h}, 35 \pm 10.5 \mathrm{~L}$. For avibactam, above mentioned parameters were $11.1 \pm 6.8$ $\mathrm{L} / \mathrm{h}, 50.8 \pm 14.3 \mathrm{~L}$. We used following equation to calculate the total body clearance $\left(C L_{t}\right): C L_{t}=C L_{s} \times C L_{C R}+C L_{i}$ [2]. $C L_{s}$ and $C L_{i}$ stand for clearance slope and intercept terms, respectively. We considered that $50 \% T_{>5 \times M I C}$ and $\backslash \% T_{>C T}(1 \mathrm{mg} / \mathrm{L})$ were the best targets to predict the microbiological outcomes of ceftazidime and avibactam for pulmonary infections, respectively [10]. CT means a minimum free avibactam concentration (threshold concentration). We applied the following equation to calculate $\% T_{>5 \times M I C}[6]$.

a. If the CZA concentration falls to the $5 \times$ MIC level after the second step of infusion is terminated:

$T_{>5 \times M I C}=T_{1}+T_{2}+\left(L N \frac{R_{02}+\left(R_{01}-R_{02}\right) \exp \left(-C L T_{2} / V_{d}\right)-R_{01} \exp \left(-C L\left(T_{1}+T_{2}\right) / V_{d}\right)}{5 \times C L \times M I C}\right) \frac{V_{d}}{C L}-\left(L N \frac{R_{01}}{R_{01}-5 \times C L \times M I C}\right) \frac{V_{d}}{C L}$

$T_{1}$ is the administration time of the first step of infusion. $T_{2}$ is the infusion time of the second step of infusion. $\mathrm{R}_{01}=$ first-dose $/ T_{1}(\mathrm{mg} / \mathrm{h}) . \mathrm{R}_{02}=$ firstdose $/ T_{2}(\mathrm{mg} / \mathrm{h})$. exp represents exponent. And $\% T_{>5 \times M I C}=\left(T_{>5 \times M I C}\right) \times \frac{100}{D I}$. DI represents the dosing interval (h). Furthermore, the $\% T_{>} \times M I C$ in $\mathrm{TI}$ was calculated using a previously published one-compartment infusion equation [11].

\subsection{Monte Carlo simulations}

Oracle Crystal Ball v.11.1.24 was used to conduct 10000 patients' Monte Carlo simulations. A log-normal distribution followed PK parameters. For each dosing regimen, the probability of target attainment (PTA) was defined as the probability of reaching the PK/PD target at each MIC. The following equation was used to calculate the cumulative fraction of response (CFR) of various dosing regimens: $\mathrm{CFR}=\sum_{i=1}^{n} P T A(M I C i) \times p(M I C i)$. MICistands for each MIC value, and $p(M I C i)$ represents a percentage of strains with this MIC. When a CFR value $\geq 90 \%$, we considered that this dosing regimen has a favorable microbiology outcome.

\section{Results}

\subsection{Probability target attainment}

The probability of target attainment (PTA) for achieving $50 \% T_{>5 \times M I C}$ for different CZA dosing models was shown in Fig. 1. For patients with normal renal function ( $\left.\mathrm{CL}_{\mathrm{CR}}>51 \mathrm{ml} / \mathrm{min}\right), \mathrm{CZA}(2.5 \mathrm{~g}$ q8h) achieved $100 \%$ target attainment when the MIC was below $8 \mathrm{mg} / \mathrm{L}$. The probability declined to $12.21 \%$ at MICs of $16 \mathrm{mg} / \mathrm{L}$. For the attainment of $50 \% T_{>5 \times M I C}$ the dosage regimens of $2.5 \mathrm{~g} \mathrm{q6h,} 4 \mathrm{~g} \mathrm{q} 8 \mathrm{~h}$, and $4 \mathrm{~g}$ q6h would be sufficient for the treatment of XDR $P$. aeruginosa with MICs $\leq 16 \mathrm{mg} / \mathrm{L}$ if administered via $2 \mathrm{~h}$ TI. If patients administered via OTAT, dosage regimens of $4 \mathrm{~g}$ [e.g., $2 \mathrm{~g}(0.5 \mathrm{~h})+2 \mathrm{~g}(2 \mathrm{~h})] \mathrm{q} 6 \mathrm{~h}$ and $4 \mathrm{~g}$ [e.g., $2 \mathrm{~g}(0.5 \mathrm{~h})+2 \mathrm{~g}(2 \mathrm{~h})$ ] q8h for the isolates with MICs of $64 \mathrm{mg} / \mathrm{L}, 2.5 \mathrm{~g}$ [e.g., $1.25 \mathrm{~g}(0.5 \mathrm{~h})+1.25 \mathrm{~g}(2 \mathrm{~h})$ ] q6h for the isolates with MICs of $32 \mathrm{mg} / \mathrm{L}, 2.5 \mathrm{~g}$ [e.g., $1.25 \mathrm{~g}(0.5 \mathrm{~h})+1.25 \mathrm{~g}(2 \mathrm{~h})$ ] q8h for the isolates with MICs of $32 \mathrm{mg} / \mathrm{L}$ produced sufficient pharmacokinetic exposures when $50 \% T_{>} 5 \times M I C$ was used as the PD target.

For patients with mild renal insufficiency $\left(\mathrm{CL}_{\mathrm{CR}}>30\right.$ to $\left.\leq 50 \mathrm{ml} / \mathrm{min}\right), \mathrm{CZA} 1.25 \mathrm{~g}$ [e.g., $\left.0.675 \mathrm{~g}(0.5 \mathrm{~h})+0.675 \mathrm{~g}(2 \mathrm{~h})\right] \mathrm{q} 8 \mathrm{~h}$ and $1.25 \mathrm{~g}$ [e.g., $0.675 \mathrm{~g}(0.5 \mathrm{~h})+$ $0.675 \mathrm{~g}(2 \mathrm{~h})]$ q6h achieved a PTA of $100 \%$ when the MIC was $16 \mathrm{mg} / \mathrm{L}$. The PTA of above OTAT dosing regimens were $100 \%$ and $95 \%$ at an MIC of $32 \mathrm{mg} / \mathrm{L}$, respectively. At an MIC of $64 \mathrm{mg} / \mathrm{L}$, PTA of OTAT were $0 \%$. For patients with $\mathrm{CL}_{\mathrm{CR}}>16$ to $\leq 30 \mathrm{ml} / \mathrm{min}$, the PTA of CZA $0.94 \mathrm{~g}$ [e.g., $0.47 \mathrm{~g}(0.5 \mathrm{~h})+0.47 \mathrm{~g}(2 \mathrm{~h})$ ] q12h were greater than $90 \%$ with MIC values of between 0.25 and $64 \mathrm{mg} / \mathrm{L}$. However, only strains with MIC $\leq 4$ can be covered by $0.94 \mathrm{~g}$ q12h if CZA administered via $2 \mathrm{~h} \mathrm{TI}$.

We have the following findings to summarize the PTA of CZA against XDR $P$. aeruginosa. In simulations of various renal functions across XDR $P$. aeruginosa pulmonary infections with MICs of 16 to $64 \mathrm{mg} / \mathrm{L}$, OTAT had a higher PTA than TI.

\subsection{Cumulative fraction of response}

Cumulative fraction of responses (CFRs) of CZA various dosing models for XDR-Pa pulmonary infections were shown in Table III. For patients with creatinine clearance $\left(\mathrm{CL}_{\mathrm{CR}}\right)>51 \mathrm{ml} / \mathrm{min}$, CFRs were $92.72 \%$ for CZA $1.25 \mathrm{~g}(0.5 \mathrm{~h})+1.25 \mathrm{~g}(2 \mathrm{~h})$ three times daily and $93.49 \%$ for CZA $1.25 \mathrm{~g}(0.5 \mathrm{~h})+1.25 \mathrm{~g}(2 \mathrm{~h})$ four times daily if administered via OTAT. For patients with $\mathrm{CL}_{\mathrm{CR}}>30$ to $\leq 50 \mathrm{ml} / \mathrm{min}, \mathrm{CFRs}$ were $93.23 \%$ for CZA $0.625 \mathrm{~g}(0.5 \mathrm{~h})+0.625 \mathrm{~g}(2 \mathrm{~h})$ three times daily and $99.29 \%$ for CZA $0.625 \mathrm{~g}(0.5 \mathrm{~h})+0.625 \mathrm{~g}(2 \mathrm{~h})$ four times daily if administered via OTAT. CFRs were $72.81 \%$ for CZA $1.25 \mathrm{~g}(2 \mathrm{~h})$ three times daily and $75.73 \%$ for CZA $1.25 \mathrm{~g}(2 \mathrm{~h})$ four times daily if administered via TI. For patients with $\mathrm{CL}_{\mathrm{CR}}>16$ to $\leq 30 \mathrm{ml} / \mathrm{min}, \mathrm{CFR}$ was for $45.38 \% \mathrm{CZA} 0.94 \mathrm{~g}$ (2h) twice daily if administered via TI and CFR was $99.62 \%$ for CZA $0.47 \mathrm{~g}(0.5 \mathrm{~h})+0.47 \mathrm{~g}(2 \mathrm{~h})$ twice daily if administered via OTAT.

Discussion 
XDR P. aeruginosa has now spread worldwide and has become a severe challenge to clinical work, especially the treatment of immunocompromised patients with severe infections [12]. Furthermore, CDC (Centers for Disease Control and Prevention) classified MDR/XDR P. aeruginosa infections as a serious antibiotic resistance threat [1]. Several studies demonstrated that clinical and microbiology responses of CZA against MDR/XDR $P$. aeruginosa pulmonary infections were inferior to other gram-negative bacteria [4, 5]. However, most of these researches were case series or retrospective studies and confined to small sample sizes. The main resistance mechanisms of $P$. aeruginosa are intrinsic resistome, mutational resistome, and horizontally acquired resistome [13]. Furthermore, CZA is a novel $\beta$-lactam/ $\beta$-lactamase inhibitors (BL/BLIs) and has been regarded as a new treatment option for XDR $P$. aeruginosa [14]. By the way, in vitro studies showed that the susceptibility rate of CZA to XDR $P$. aeruginosa ranged from 73.7-76.2\% [8, 15, 16].

Based on the above research background, our team conducted a PK/PD analysis. In our study, we used OTAT and TI to evaluate the efficacy of different CZA dosing models to treat XDR P. aeruginosa pulmonary infections. MCSs have been performed to study CZA dosing models and define the optimal dosing regimen of CZA therapy for XDR $P$. aeruginosa pneumonia, testing various renal function statuses and doses.

And we found that all OTAT dosing regimens (ie: $2.5 \mathrm{~g}$ [e.g., $1.25 \mathrm{~g}(0.5 \mathrm{~h})+1.25 \mathrm{~g}(2 \mathrm{~h})] \mathrm{q} 6 \mathrm{~h}, 2.5 \mathrm{~g}$ [e.g., $1.25 \mathrm{~g}(0.5 \mathrm{~h})+1.25 \mathrm{~g}(2 \mathrm{~h})] \mathrm{q} 8 \mathrm{~h}, 4 \mathrm{~g}$ [e.g., $2 \mathrm{~g}(0.5 \mathrm{~h})+2$ $\mathrm{g}(2 \mathrm{~h})$ ] q6h, $4 \mathrm{~g}$ [e.g., $2 \mathrm{~g}(0.5 \mathrm{~h})+2 \mathrm{~g}(2 \mathrm{~h})] \mathrm{q} 8 \mathrm{~h}$ for normal renal function patients. $1.25 \mathrm{~g}$ [e.g., $0.675 \mathrm{~g}(0.5 \mathrm{~h})+0.675 \mathrm{~g}(2 \mathrm{~h})] \mathrm{q} 6 \mathrm{~h}, 1.25 \mathrm{~g}[\mathrm{e} . \mathrm{g} ., 0.675 \mathrm{~g}(0.5 \mathrm{~h})+$

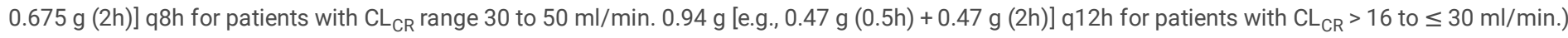
with adequate PK exposures (CZA concentration decreased to $5 \times$ MIC after the second step infusion) can obtain favorable response. Compared with TI, we considered that OTAT can be an ideal strategy for XDR P. aeruginosa with MICs of 16 to $32 \mathrm{mg} / \mathrm{L}$.

Eguchi et al. (2010) [6] conducted a PK/PD analysis, and they found that OTAT can significantly improve the initial killing rate of meropenem. Another study demonstrated that meropenem monotherapy is competent for meropenem-nonsusceptible bacterial infections if administered rational OTAT [11]. These were similar to the results of our study. As with other time depended antibiotics (i.e., meropenem, ceftazidime), administration by OTAT is a potential treatment option for improving the probability of attaining the PK/PD target.

In clinical setting, drug-resistant $P$. aeruginosa in the respiratory tract is often found in patients with chronic lung disease states such as cystic fibrosis, immunosuppression, and so on. Considering that patient population can affect treatment decision and has varying PK/PD parameters, I suggest that the application of OTAT regimens should be considered the variation of PK parameters.

From the pharmacoeconomic perspective, our study has great significance for some developing countries with poor healthcare situations. At the same dosing model (i.e., same medical expenses), OTATs with sufficient PK exposures were more effective than TI. CZA is a novel antibiotic with high prices. In case of poor efficacy of CZA therapy for XDR P. aeruginosa pneumonia, doctors can use an OTAT rather than increasing the dose or frequency blindly. This can significantly reduce the burden on patients.

From the perspective of safety of CZA, our study helps to reduce toxic reactions caused by overdose. At the standard dose of CZA ( $2.5 \mathrm{~g}$ q8h), the TI does not provide good bactericidal effect for XDR $P$. aeruginosa pulmonary infections, but the OTAT provides good bactericidal effect for XDR $P$. aeruginosa pneumonia. There are limits to the effectiveness of attempts to increase doses to achieve therapeutic goals, and the risk of overdose should be taken into account.

Our work had several limitations, as follows. Firstly, PK parameters of ceftazidime and avibactam were obtained from critically ill patients' serum samples and confined to its small sample size. Nevertheless, our study aimed to evaluate the efficacy of CZA for the treatment of XDR $P$. aeruginosa pneumonia. Epithelial lining fluid (ELF) samples of patients with pneumonia would be the best [17].

Secondly, local surveillance and epidemiology should always be considered when deciding a therapy for drug-resistant organisms. Knowing resistance patterns is a key to control antimicrobial resistance as well as to avoid any antibiotic misuse or overuse. Therefore, applicability of MICs from a different country should be considered with caution as the strategies against multi-drug organisms (MDRO) may differ country by country, state by state, and even city by city. XDR P. aeruginosa was isolated from the United States from 2012 to 2015. XDR P. aeruginosa were collected in recent years would be better, but MIC distributions of these strains were unavailable.

Alternative regimens included longer dosage interval, prolonged infusions of the full dose for both drugs and OTAT. In addition, those regimens could reduce dosing errors, drug cost and nurse labor. Clinical investigation of those alternative dosage regimens would be required before implementation.

The treatment of XDR P. aeruginosa pulmonary infections is a massive challenge in our future work. In this study, we conducted Monte Carlo simulations to evaluate the efficacy of CZA for the treatment of XDR $P$. aeruginosa pulmonary infections. We found that OTAT dosing regimens can vastly improve the PTA at MIC $\geq 16 \mathrm{mg} / \mathrm{L}$. Moreover, all OTAT dosing regimens can obtain favorable CFR values.

\section{Conclusion}

In conclusion, OTAT with sufficient pharmacokinetic exposures can improve the efficacy of CZA for the treatment of XDR P. aeruginosa pulmonary infections.

\section{Declarations}

\section{Ethics approval and consent to participate}

Not applicable. 
Not applicable.

Availability of data and materials

All data generated or analysed during this study are included in this published article.

Funding

This work was supported by the Military biosafety research fund (No. 19SWAQ06) and the "13th Five-Year" Military Key Discipline Construction Project of the PLA Medical College.

\section{Competing interests}

The authors declare that they have no competing interests.

\section{Authors' contributions}

The manuscript was written by Yixin Kang and revised by Junchang Cui.

\section{Acknowledgements}

I would like to thank my mentor, Professor Cui, for his tremendous help in my studies and in my life. And I would like to thank the Chinese People's Liberation Army General Hospital for their financial support.

All methods were performed in accordance with the relevant guidelines and regulations

\section{References}

1. Horcajada JP, Montero M, Oliver A, Sorli L, Luque S, Gomez-Zorrilla S, Benito N, Grau S: Epidemiology and Treatment of Multidrug-Resistant and Extensively Drug-Resistant Pseudomonas aeruginosa Infections. Clin Microbiol Rev 2019, 32(4).

2. Stein GE, Smith CL, Scharmen A, Kidd JM, Cooper C, Kuti J, Mitra S, Nicolau DP, Havlichek DH: Pharmacokinetic and Pharmacodynamic Analysis of Ceftazidime/Avibactam in Critically III Patients. Surg Infect (Larchmt) 2019, 20(1):55-61.

3. https://mic.eucast.org/Eucast2 Accessed 2021 Nov 25th.

4. Torres A, Zhong N, Pachl J, Timsit J-F, Kollef M, Chen Z, Song J, Taylor D, Laud PJ, Stone GG et al: Ceftazidime-avibactam versus meropenem in nosocomial pneumonia, including ventilator-associated pneumonia (REPROVE): a randomised, double-blind, phase 3 non-inferiority trial. The Lancet Infectious Diseases 2018, 18(3):285-295.

5. Stone GG, Newell P, Gasink LB, Broadhurst H, Wardman A, Yates K, Chen Z, Song J, Chow JW: Clinical activity of ceftazidime/avibactam against MDR Enterobacteriaceae and Pseudomonas aeruginosa: pooled data from the ceftazidime/avibactam Phase III clinical trial programme. J Antimicrob Chemother 2018, 73(9):2519-2523.

6. Eguchi K, Kanazawa K, Shimizudani T, Kanemitsu K, Kaku M: Experimental verification of the efficacy of optimized two-step infusion therapy with meropenem using an in vitro pharmacodynamic model and Monte Carlo simulation. J Infect Chemother 2010, 16(1):1-9.

7. Kang Y, Zhou Q, Cui J: Pharmacokinetic/pharmacodynamic modelling to evaluate the efficacy of various dosing regimens of ceftazidime/avibactam in patients with pneumonia caused by Klebsiella pneumoniae carbapenemase (KPC)-producing K. pneumoniae: a multicentre study in northern China. J Glob Antimicrob Resist 2021, 27:67-71.

8. Sader HS, Huband MD, Castanheira M, Flamm RK: Pseudomonas aeruginosa Antimicrobial Susceptibility Results from Four Years (2012 to 2015) of the International Network for Optimal Resistance Monitoring Program in the United States. Antimicrob Agents Chemother 2017, 61(3).

9. ceftazidime and avibactam sodium for injection. https://reference.medscape.com/drug/avycaz-ceftazidime-avibactam-999985. Product information.

10. Andes D, Craig WA: Animal model pharmacokinetics and pharmacodynamics: a critical review. Int J Antimicrob Agents 2002, 19(4):261-268.

11. Song X, Wu Y, Cao L, Yao D, Long M: Is Meropenem as a Monotherapy Truly Incompetent for Meropenem-Nonsusceptible Bacterial Strains? A Pharmacokinetic/Pharmacodynamic Modeling With Monte Carlo Simulation. Front Microbiol 2019, 10:2777.

12. Poole K: Pseudomonas aeruginosa: resistance to the max. Front Microbiol 2011, 2:65.

13. Breidenstein EB, de la Fuente-Núñez C, Hancock RE: Pseudomonas aeruginosa: all roads lead to resistance. Trends Microbiol 2011, 19(8):419-426.

14. Sy SK, Zhuang L, Beaudoin ME, Kircher P, Tabosa MA, Cavalcanti NC, Grunwitz C, Pieper S, Schuck VJ, Nichols WW et al: Potentiation of ceftazidime by avibactam against $\beta$-lactam-resistant Pseudomonas aeruginosa in an in vitro infection model. J Antimicrob Chemother 2017, 72(4):1109-1117.

15. Sader HS, Castanheira M, Flamm RK, Mendes RE, Farrell DJ, Jones RN: Ceftazidime/avibactam tested against Gram-negative bacteria from intensive care unit (ICU) and non-ICU patients, including those with ventilator-associated pneumonia. Int J Antimicrob Agents 2015, 46(1):53-59.

16. Sader HS, Castanheira M, Flamm RK: Antimicrobial Activity of Ceftazidime-Avibactam against Gram-Negative Bacteria Isolated from Patients Hospitalized with Pneumonia in U.S. Medical Centers, 2011 to 2015. Antimicrob Agents Chemother 2017, 61(4). 
17. Nicolau DP, Siew L, Armstrong J, Li J, Edeki T, Learoyd M, Das S: Phase 1 study assessing the steady-state concentration of ceftazidime and avibactam in plasma and epithelial lining fluid following two dosing regimens. J Antimicrob Chemother 2015, 70(10):2862-2869.

\section{Tables}

Table I. MIC distribution of ceftazidime-avibactam (CZA) monotherapy for extensively drug-resistant (XDR) P. aeruginosa isolates from four years (2012 to 2015) of the International Network for Optimal Resistance Monitoring Program in the United States.

\begin{tabular}{|lllllllllll|}
\hline \multicolumn{1}{c|}{ Number of isolates at MIC (mg/liter) } \\
& $\leq 0.25$ & 0.5 & 1 & 2 & 4 & 8 & 16 & 32 & 64 \\
XDR P. aeruginosa & 1 & 4 & 28 & 109 & 179 & 208 & 88 & 36 & 45 \\
\hline
\end{tabular}

Table II. Simulated dosing models of ceftazidime-avibactam (CZA).

\begin{tabular}{|c|c|c|c|}
\hline \multirow[t]{2}{*}{ Renal status } & \multirow[t]{2}{*}{ Dosing models } & \multicolumn{2}{|c|}{ Simulated dosing regimens } \\
\hline & & TI & OTAT \\
\hline \multirow[t]{4}{*}{$\mathrm{CL}_{\mathrm{CR}}>51 \mathrm{ml} / \mathrm{min}$} & $2.5 \mathrm{~g} \mathrm{q} 8 \mathrm{~h}$ & $2.5 \mathrm{~g}(2 \mathrm{~h})$ & $1.25 g(0.5 h)+1.25 g(2 h)$ \\
\hline & $2.5 \mathrm{~g} \mathrm{q6h}$ & $2.5 \mathrm{~g}(2 \mathrm{~h})$ & $1.25 \mathrm{~g}(0.5 \mathrm{~h})+1.25 \mathrm{~g}(2 \mathrm{~h})$ \\
\hline & $4 \mathrm{~g} \mathrm{q} 8 \mathrm{~h}$ & $4 g(2 h)$ & $2 g(0.5 h)+2 g(2 h)$ \\
\hline & $4 g$ q6h & $4 \mathrm{~g}(2 \mathrm{~h})$ & $2 g(0.5 h)+2 g(2 h)$ \\
\hline \multirow[t]{2}{*}{$30 \mathrm{ml} / \mathrm{min}<\mathrm{CL}_{\mathrm{CR}} \leq 50 \mathrm{ml} / \mathrm{min}$} & $1.25 \mathrm{~g} \mathrm{q} 8 \mathrm{~h}$ & $1.25 \mathrm{~g}(2 \mathrm{~h})$ & $0.625 g(0.5 h)+0.625 g(2 h)$ \\
\hline & $1.25 \mathrm{~g} \mathrm{q} 6 \mathrm{~h}$ & $1.25 \mathrm{~g}(2 \mathrm{~h})$ & $0.625 g(0.5 h)+0.625 g(2 h)$ \\
\hline $16 \mathrm{ml} / \mathrm{min}<\mathrm{CL}_{\mathrm{CR}} \leq 30 \mathrm{ml} / \mathrm{min}$ & $0.94 \mathrm{~g} \mathrm{q} 12 \mathrm{~h}$ & $0.94 \mathrm{~g}(2 \mathrm{~h})$ & $0.47 g(0.5 h)+0.47 g(2 h)$ \\
\hline
\end{tabular}

TI: traditional infusion, OTAT: optimized two-step-administration therapy.

Table III. Cumulative fraction of responses (CFRs) for various dosing regimens of ceftazidime-avibactam (CZA) against XDR P. aeruginosa.

\begin{tabular}{|c|c|c|}
\hline Dosing models & Simulated dosing regimens & CFRs (\%) \\
\hline \multirow[t]{2}{*}{$2.5 \mathrm{~g} \mathrm{q} 8 \mathrm{~h}$} & $2.5 \mathrm{~g}(2 \mathrm{~h})$ & 77.27 \\
\hline & $1.25 \mathrm{~g}(0.5 \mathrm{~h})+1.25 \mathrm{~g}(2 \mathrm{~h})$ & 92.72 \\
\hline \multirow[t]{2}{*}{$2.5 \mathrm{~g} \mathrm{q} 6 \mathrm{~h}$} & $2.5 \mathrm{~g}(2 \mathrm{~h})$ & 88.34 \\
\hline & $1.25 \mathrm{~g}(0.5 \mathrm{~h})+1.25 \mathrm{~g}(2 \mathrm{~h})$ & 93.49 \\
\hline \multirow[t]{2}{*}{$4 \mathrm{~g} \mathrm{q8h}$} & $4 g(2 h)$ & 89.11 \\
\hline & $2 g(0.5 h)+2 g(2 h)$ & 99.83 \\
\hline \multirow[t]{2}{*}{$4 \mathrm{~g} \mathrm{q6h}$} & $4 g(2 h)$ & 88.34 \\
\hline & $2 g(0.5 h)+2 g(2 h)$ & 99.29 \\
\hline \multirow[t]{2}{*}{$1.25 \mathrm{~g} \mathrm{q} 8 \mathrm{~h}$} & $1.25 \mathrm{~g}(2 \mathrm{~h})$ & 72.81 \\
\hline & $0.625 g(0.5 h)+0.625 g(2 h)$ & 93.23 \\
\hline \multirow[t]{2}{*}{$1.25 \mathrm{~g} \mathrm{q6h}$} & $1.25 \mathrm{~g}(2 \mathrm{~h})$ & 75.73 \\
\hline & $0.625 g(0.5 h)+0.625 g(2 h)$ & 99.34 \\
\hline \multirow[t]{2}{*}{$0.94 \mathrm{~g} \mathrm{q} 12 \mathrm{~h}$} & $0.94 \mathrm{~g}(2 \mathrm{~h})$ & 45.38 \\
\hline & $0.47 g(0.5 h)+0.47 g(2 h)$ & 99.62 \\
\hline
\end{tabular}

\section{Figures}



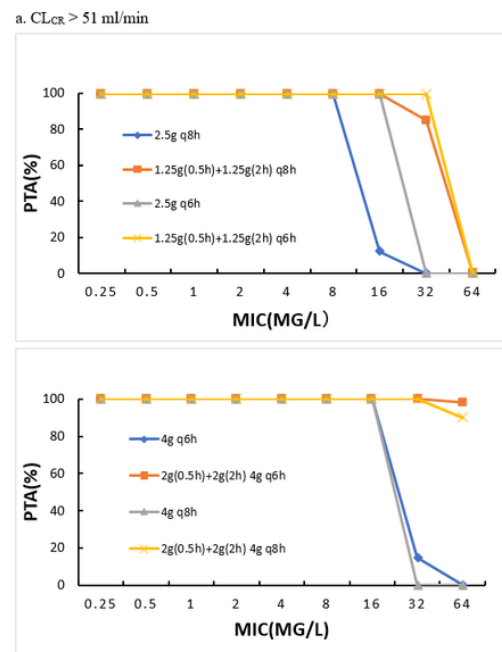

b. $30 \mathrm{ml} / \min <\mathrm{CL}_{\mathrm{CR}} \leq 50 \mathrm{ml} / \mathrm{min}$
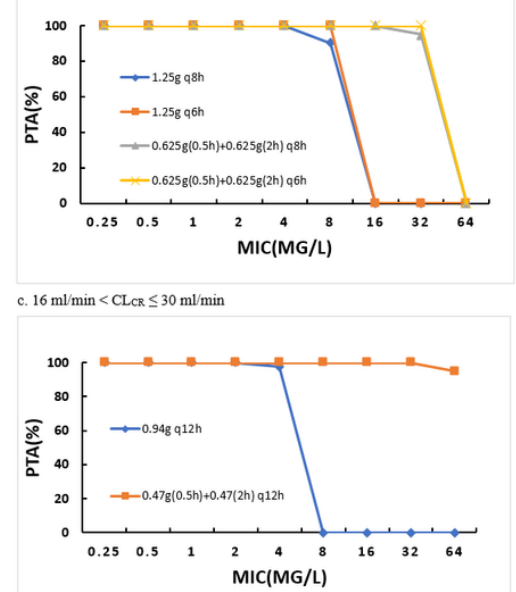

Figure 1

The probability of target attainment for achieving $50 \% T>5 \times \mathrm{MIC}$ for different ceftazidime-avibactam dosing regimens.

a. $\mathrm{CL}_{\mathrm{CR}}>51 \mathrm{ml} / \mathrm{min}$, b. $30 \mathrm{ml} / \mathrm{min}<\mathrm{CL}_{\mathrm{CR}} \leq 50 \mathrm{ml} / \mathrm{min}$, c. $16 \mathrm{ml} / \mathrm{min}<\mathrm{CL}_{\mathrm{CR}} \leq 30 \mathrm{ml} / \mathrm{min}$. 